\title{
François Jost: entre a intimidade e a maldade (comunicação, personagens e séries de televisão na atualidade)
}

Maria Cristina Palma Mungioli

Professora doutora do Departamento de Comunicações e Artes e do Programa de Pós-Graduação em Ciências da Comunicação da Escola de Comunicações e Artes da Universidade de São Paulo (ECA/USP). Lider do Grupo de Pesquisa (CNPq) Linguagens e Discursos nos Meios de Comunicações (GELiDis).

E-mail: crismungioli@gmail.com

Resumo: O professor e pesquisador francês François Jost tem se dedicado aos estudos da comunicação e, mais especificamente, aos estudos de cinema e televisão a partir de diferentes perspectivas e abordagens. É professor emérito de ciências da informação e da comunicação da Universidade Sorbonne Nouvelle - Paris 3, na qual fundou, em 1996, o Centro de Estudos de Imagens e Sons (CEISME), que coordenou até 2016. Na mesma universidade, dirigiu o Laboratório de Comunicação, Informação e Mídias (CIM), de 2012 a 2016. Dirige a revista Télévision, publicada pela CNRS éditions (editora do Centre National de Recherches Scientifiques - CNRS). Tem sido professor convidado em universidades europeias, latino-americanas e canadenses. Cabe destacar ainda que os resultados de suas pesquisas nesses centros bem como os seminários e conferências realizados no Brasil têm impactado os estudos de televisão em nosso país. Possui dezenas de livros publicados na França, muitos dos quais foram traduzidos para outros idiomas.
Abstract: The French professor and researcher François Jost has dedicated himself to Communication Studies and, more specifically, to Cinema and Television Studies based on several perspectives and approaches. He is an Emeritus Professor of Information and Communication Sciences at University Sorbonne Nouvelle - Paris 3, where he founded the Center for the Study of Images and Sounds (CEISM) in 1996, which he coordinated until 2016. At the same University, he directed the laboratory of Communication, Information and Media (CIM) from 2012 to 2016. $\mathrm{He}$ directs the magazine Télévision, published by the CNRS éditions (Centre National de Recherches Scientifiques CNRS publishing house). He is a visiting professor in many European, LatinAmerican and Canadian universities. It is worth mentioning that the results of their research in these centers, as well as seminars and conferences conducted in Brazil, have impacted television studies in our country. He has dozens of books published in France, many of which were translated into other languages.
Recebido: 19/01/2018

Aprovado: 01/03/2018 
No Brasil publicou, até o momento, Seis lições sobre a televisão, em 2004, A narrativa cinematográfica, escrito em coautoria com André Gaudreault, em 2009, Compreender a televisão, em 2010, e Do que as séries americanas são sintoma?, em 2012. Dois de seus mais recentes livros, Les nouveaux méchants: quand les séries américaines font bouger les lignes du bien et $d u$ mal' e La méchanceté en actes à l'ère numérique ${ }^{2}$, servem como pano de fundo para algumas das questões desta entrevista.

Palavras-chave: estudos de televisão; séries de televisão; comunicação na internet; análise de séries de televisão.
In Brazil, so far, he published Seis lições sobre a televisão, in 2004, A narrativa cinematográfica, with André Gaudreault as co-author, in 2009, Compreender a televisão, em 2010, and Do que as séries americanas são sintoma, in 2012. Two of his most recent books, Les nouveaux méchants: quand les séries américaines font bouger les lignes du bien et du mal ${ }^{3}$ and La méchanceté en actes à l'ère numérique ${ }^{4}$ serve as grounds for some of the questions in this interview.

Keywords: television studies; television series; communication on the internet; analysis of television series.

\section{Comunicação $\mathfrak{E}$ Educação: Um ponto comum em sua obra, no que se refere ao} estudo da televisão, tem sido a defesa da elaboração e do uso de conceitos e metodologias próprios ao universo da televisão. Por que esse posicionamento é necessário tanto para o estudo da televisão como meio quanto para seus conteúdos?

François Jost: No início, principalmente na França, a televisão foi estudada do ponto de vista sociológico e econômico, mas a partir do momento em que pudemos aceder, particularmente na França, aos arquivos de programas de televisão, encontrei-me diante de um corpus enorme, de um número enorme de gêneros de emissões. Eu não sabia como analisá-los, então me dei conta de que os métodos que havia herdado do cinema não eram suficientes, porque o cinema na época era um pouco o sucesso do ano. Estudavam-se essencialmente as obras - os textos, em particular.

No caso da televisão, havia a dificuldade do grande corpus para análise. Os métodos que eram essencialmente de análise da história ou do enredo não davam conta de outros pontos importantes. Parece-me que um desses pontos é a estruturação que a televisão realiza em relação ao nosso próprio tempo. Enquanto o tempo em que vamos ao cinema é um tempo meio que entre parênteses (vamos ao cinema e depois pensamos em outra coisa), a televisão

1. “Os novos [personagens] maus: quando as séries americanas estremecem as linhas do bem e do mal" (tradução livre).

2. "Atos de maldade na era da internet" (tradução livre).

3. "The new bad [characters]: when American series shake the lines of good and evil" (free translation).

4. "Acts of malice in the internet age" (free translation). nos acompanha em nossa vida, no cotidiano. Assim, a ênfase nos estudos não deveria ser dada tanto à análise, por exemplo, de mudanças de plano. Era preciso encontrar outros métodos, e isso me levou a deslocar a unidade de análise. Em lugar de trabalhar com os planos, como se fazia com os filmes, tive a impressão de que era preciso trabalhar com os gêneros que contêm os programas e depois com aquilo que chamo de "o mundo da televisão" - que, por sua vez, contém os gêneros. Assim, os métodos que podiam ser aplicados ao cinema não eram mais válidos para a televisão, e questões como quem transmite os programas tornam-se importantes para o estudo desta.

Comecei a estudar a questão da enunciação televisual em 1987, observando que a enunciação televisiva não ocorre da mesma forma que a enunciação do 
filme, já que na enunciação cinematográfica podíamos permanecer dentro do filme e ver, por exemplo, em que momento se saía da transparência e se chegava ao uso enunciativo dos signos. Assim, muito rápido, comecei a colocar-me a questão da instituição televisiva que fala por meio dos programas. A questão da autoria não segue a mesma linha do cinema, já que, com frequência, não se conhecem os autores dos programas. De outra parte, para mim, a televisão começa bem antes da transmissão do programa: há a promoção, as entrevistas dos produtores... Ou seja, promessas do que será o produto. E tudo isso não existia na teoria do cinema. No entanto, como uma espécie de retorno das coisas, podemos aplicar essa ideia ao cinema - alguns pesquisadores até já fizeram isso.

$C \mathcal{E}{ }^{2} E$ : As séries estão entre os formatos mais longevos da televisão, presentes na programação desde os primórdios desse meio em diversos países, inclusive no Brasil. Poderíamos dizer que o formato se reinventa a partir do próprio caráter híbrido e fragmentário da programação de televisão que acompanha o cotidiano das pessoas? E, nessa direção, como os reality shows - formato mais recente, mas também onipresente na televisão em escala mundial - influenciou as séries, sobretudo a partir do ano 2000?

FJ: O ponto importante é que as séries recentes, sobretudo as estadunidenses, evoluíram em direção à intimidade. Ainda é preciso definir o que é intimidade, mas ocorre que as séries, mais ou menos até 1990, reservavam pouco espaço para a intimidade. Por exemplo, sabíamos que em Starsky and $H u t c h^{5}$, se um dos personagens namorava uma moça em um episódio, no seguinte ela não apareceria mais. A mesma coisa ocorria com a série Columbo ${ }^{6}$ : o detetive falava de sua mulher, mas não a víamos. Evocava-se a vida particular, mas era apenas isso.

A partir dos anos 1990, as personagens das séries possuem uma vida privada com certa incidência sobre a condução da narrativa; há cenas de intimidade sexual ou alguma coisa desse tipo. Há também, de maneira muito importante, o uso frequente de voice over explicitando o sentimento da personagem, mas não são vozes como as do film noir, que informam alguma coisa que não tínhamos visto; são vozes que dizem dos sentimentos da personagem. Portanto, há uma ênfase sobre a vida privada.

$\mathrm{E}$ os reality shows são também um lugar cujo sucesso se deve muito ao fato de se mostrar e colocar como espetáculo a vida privada, de modo que esta se torna, de repente, publicizada. Acredito que uma coisa muito interessante da televisão é misturar as pessoas, ver como evolui a ficção e os reality shows, e perceber como há coisas que convergem. Esse retorno ao indivíduo como tal, não apenas uma visão exterior dele, me agrada, como as pequenas coisas do dia a dia. Geralmente, cita-se como um marco a série Hill Street Blues ${ }^{7}$, que começou em 1981. Nela vemos a vida em uma delegacia de polícia, na qual as personagens não são mais heróis perfeitos - há um que bebe, outro cujo filho se droga, outro que tem problemas com a mulher. Tudo isso mostra um jogo que não se via antes. Em geral, os heróis das séries anteriores eram pouco
5. Série estadunidense produzida pela rede $A B C$ que foi ao ar de 1975 a 1979 e teve 92 episódios.

6. Série estadunidense produzida pela NBC (19681978) e pela ABC (19892003), com 69 episódios no total.

7. Série estadunidense produzida pela rede NBC de 1981 a 1987. Teve um total de 146 episódios. 
humanos, simplesmente heróis. Outra coisa diferente é que, apesar de a figura do policial já ter sido mostrada em inúmeras outras séries, e de geralmente ser ele quem resolvia grandes problemas, nessa série o que precisava ser solucionado eram os pequenos problemas do bairro, de vizinhança.

CEEE: Como você acabou de mencionar, um recurso que geralmente acompanha o emprego do voice over nas séries mais recentes refere-se ao uso de imagens para ilustrar memórias das personagens. Como você vê o uso desse recurso para a construção de personagens?

FJ: Há um teórico, chamado Nortop Frye, que estuda a posição que tem o leitor em relação à personagem. Ele diz que há ficções nas quais o herói pode agir sobre o ambiente humano e natural. É o herói da mitologia - ou, pensando nas séries, seria uma espécie de Superman. Também há o herói que tem um talento, um dom superior ao de todos os humanos. E finalmente há o herói mimético, que tem o mesmo poder que nós, leitores. Frye observou isso em relação à literatura, mas se pode observar o mesmo em relação a séries. Pode-se observar como nas séries se passa progressivamente do herói todo poderoso - na minha opinião, ainda muito importante para o cinema - para os heróis que querem nos cativar no cotidiano; vemos progressivamente essa humanização dos heróis. E vejo esse mesmo movimento nos reality shows. Esses aspectos participam desse mesmo movimento de humanização das personagens que, por meio dessa construção, se parecem conosco.

$C{ }^{2} E$ : Entre seus trabalhos mais recentes destacam-se livros e artigos que tratam das séries de televisão. No livro Do que as séries americanas são sintoma? você fala que a seriefilia substituiu a cinefilia. É possível encontrar/definir um momento em que isso ocorreu? $O$ que mudou as séries ou o público?

FJ: Acho bem interessante essa questão sobre se o que mudou foram as séries ou o público. Penso que as duas coisas são verdadeiras. O que mudou mesmo com a chegada de séries em canais pagos como HBO ou AMC, de uma maneira bastante forte, foi o conhecimento que temos dos autores e até mesmo dos criadores das ficções. Antes, apenas algumas pessoas sabiam isso. Uma segunda coisa que mudou foi o fato de que essas séries entraram em detalhes, com uma atenção maior à mise-en-scène - algo bem diferente quando as comparamos com as séries mais antigas. Por exemplo, quando vemos Walter White ${ }^{9}$ preparando um suco de laranja para sua mulher, vemos alguém que faz coisas como nós, uma personagem que se parece conosco.

Mas o que também acho determinante é que os instrumentos para ver as

8. JOST, F. Do que as séries americanas são sintoma? Porto Alegre: Sulina, 2012 $70 \mathrm{p}$.

9. Protagonista da série estadunidense Breaking Bad, produzida pela AMC, exibida de 2008 a 2013, com 62 episódios. séries mudaram. Nós as vemos em tablets, computadores, televisão. Adquirimos o hábito de parar uma cena para revê-la em detalhes, de aumentar a imagem para ver algum detalhe, de voltar à cena anterior etc. E os roteiristas, na minha opinião, passaram a levar em conta isso também. Então escrevem séries que não podemos ver como víamos as séries de antigamente. É preciso estar sempre muito atento aos detalhes. Portanto o objeto mudou, e há uma interação entre 
essa mudança do objeto e do público. Há também uma questão ligada à tecnologia que diz respeito diretamente ao crescimento da internet e ao fato de que, quando se vê uma série, podemos compartilhar nossas impressões. As páginas wikis ${ }^{10}$ são exemplos dessa construção compartilhada. Há ainda pessoas que são verdadeiros especialistas e podem interagir com outras pessoas, construindo assim a seriefilia.

CEEE: Os chamados "heróis sem caráter" ou de caráter duvidoso fazem parte da literatura há bastante tempo, e também do cinema. Heróis picarescos, malandros, personagens ambíguos e vilóes compõem um vasto rol de personagens que amedrontam e encantam leitores e espectadores. Porém, em termos de séries de televisão, é relativamente recente o surgimento de tais heróis. Na sua opinião, quais teriam sido os motivos para isso? Esse surgimento pode ser visto em termos de construção, pela televisão, de um discurso "realista" sobre a sociedade?

FJ: Aqui mais uma vez voltamos à questão dos canais pagos, porque os canais abertos não podiam dizer palavrões ou mostrar cenas de sexo, por exemplo. Isso mudou principalmente desde que, em 1997, a HBO produziu a série $O z^{11}$ com palavrões e cenas extremamente realistas de sexo. Poderíamos dizer que é um certo extravasamento daquilo que ficou por muito tempo reprimido, sem poder ser expresso ou mostrado. É verdade, há todo um movimento que faz com que os heróis não sejam mais personagens desencarnados, que resistem a tudo e que devem superar tudo, sem deixarem de ser bons. Há, portanto, a invenção de um herói que não se parece com os anteriores das séries de televisão.

Devemos ainda lembrar que, como dizia Hitchcock, "quanto melhor a personagem má, melhor a história”. A personagem gentil é interessante desde que possa lutar contra os malvados. O que mudou em relação às personagens más é que anteriormente os malvados eram maus o tempo todo. Por exemplo, JR (um dos protagonistas da série Dallas $^{12}$ ) era mau o tempo todo: nos negócios, com a família, com os filhos, com a mulher. $\mathrm{O}$ que temos agora são heróis malvados que são mais humanos, capazes de ser amorosos em diversos momentos e de amar os filhos, por exemplo. Na literatura isso ocorreu há mais tempo, mas acredito que na televisão a mudança demorou um pouco mais para acontecer por razões morais e de censura. Ainda mais se lembrarmos que nos EUA houve o Code Hays ${ }^{13}$ e o Television $C o d e^{14}$, o qual exigia, por exemplo, que se em uma ficção alguém matasse uma pessoa, o assassino deveria morrer ao final da história. $\mathrm{O}$ assassino não poderia escapar ou ser salvo; de maneira exemplar, deveria ser condenado à morte. Era até um pouco enfadonho saber de antemão que o assassino iria morrer ao final. $\mathrm{Ou}$ seja, em histórias desse tipo, já sabíamos o final sempre.

Hoje, principalmente com as séries estadunidenses, nunca sabemos o final. $\mathrm{E}$ às vezes somos surpreendidos quando, por exemplo, em House of Cards ${ }^{15}$, Frank Underwood de repente mata a jovem com quem mantinha uma relação amorosa. Não esperávamos por isso, mesmo sabendo que ele é um cínico. Acho que aqui podemos encontrar algo que interessa, pois há uma verdadeira
10. Wiki é um website que geralmente permite que qualquer pessoa possa modificar o conteúdo disponível nele. Uma página wiki utiliza um código fácil de editar que permite que se utilizem textos, links e imagens sem a necessidade de aprendizado de códigos de programação. Disponível em: https://goo.gl/Da17F4. Acesso em: 24 maio 2018.

11. Série estadunidense exibida pela HBO de 1997 a 2003, com 53 episódios.

12. Série estadunidense exibida pela CBS de 1978 a 1991, com 357 episódios. De 2012 a 2014, a série é retomada retratando a vida dos herdeiros da família Ewing.

13. Code Hays (Código Hays) é o nome com que ficou conhecido o Motion Picture Production Code (Código de Produção de Cinema). Trata-se de um conjunto de normas morais aplicadas aos filmes lançados nos Estados Unidos entre 1930 e 1968 pelos grandes estúdios cinematográficos. O código de autocensura explicitava qual conteúdo era aceitável ou não para os filmes produzidos nos Estados Unidos.

14. O Código de Televisão (Television Code) é uma forma abreviada de se referir ao Código de Práticas para Emissoras de Televisão (aberta) (The Code of Practices for Television Broadcasters). Tratava-se de um conjunto de regras éticas adotadas pela Associação Nacional de Emissoras de Televisão (National Association of Broadcasters), nos EUA. O código foi criado em dezembro de 1951 e vigorou até 1983.

15. Série estadunidense lançada em 2013 e exibida pela Netflix. É uma adaptação da série homônima exibida pela BBC em 1990 que, por sua vez, é baseada no livro de mesmo nome de Michael Dobbs. 
transformação moral que, com certeza, tem a ver com questões sociológicas. Minha hipótese é de que há uma perda de confiança crescente nas instituições. Cada vez menos se confia nelas: pensa-se que a justiça (o poder judiciário) liberta os criminosos, que o serviço de saúde pública é negligente etc. Nem todos acham isso, mas muitas pessoas pensam dessa forma. E isso faz com que em determinados momentos haja pessoas (e personagens) que se revoltam contra a sociedade, praticando atividades delinquentes ou fora da norma social. Portanto isso é bem diferente das personagens más dos filmes de faroeste que, boa parte das vezes, lutavam pelo bem da sociedade ou, pelo menos, de uma parcela dela. Agora as soluções são mais individualistas.

CEEE: Em um de seus livros mais recentes, Les Nouveaux Méchants ${ }^{16}$, você analisa personagens más de séries atuais (Deadwood ${ }^{17}$, Breaking Bad, Dexter ${ }^{18}$ ) contrapondo-as, em termos de valores, aos heróis dos filmes de faroeste americanos, que forjaram uma espécie de mitologia estadunidense de país e de povo, construindo assim uma representação identitária do país. Essa representação do que é ser "norte-americano" estende-se para outros países devido à difusão de filmes e séries das poderosas indústrias de cinema e televisão dos EUA. Nesse sentido, o que as séries estadunidenses com vilões, como os analisados em seu livro, mostram ao público estadunidense e de outros países?

FJ: No que pude observar em relação aos EUA, uma das noções-chave no cotidiano norte-americano é a noção de comunidade. Devem-se fazer as coisas para a comunidade. Analisei três séries: Deadwood, Dexter e Breaking Bad. Deadwood é um faroeste, mas é bem diferente daqueles que vemos no cinema. Essa série mostra o nascimento de uma pequena cidade, no atual estado de Dakota, que no início da história ainda não faz parte dos EUA. Na série, vemos a construção dessa cidade cujo pastor pede a todos os moradores que tenham um espírito de comunidade, como se fossem parte de um corpo que trabalha para um organismo único. Nessa cidade, há personagens maus, sobretudo um que vai chegar ao final, chamado Hearst - que é de fato (na vida real) o pai daquele que vai se tornar o grande magnata da imprensa estadunidense ${ }^{19}$. Ele chega à cidade e, por um lado, toma conta da imprensa local e a submete à sua própria vontade; por outro, mata as pessoas que o incomodam. Esse homem não foi assim na vida real; creio que foi um senador bastante estimado, representando a chegada de um capitalismo extremamente duro que, de certa maneira, desfaz os laços dessa comunidade.

Em Breaking Bad e Dexter vemos que não há mais tal espírito de comunidade - é cada um por si. As leis e os políticos não conseguem fazer com que as instituições funcionem e, portanto, há apenas respostas individuais. Dexter mata inocentes porque considera que a polícia os liberta devido a um sistema judiciário falho. Portanto há uma espécie de perda da ideia de comunidade, que leva à emergência desses novos [personagens] maus, como Walter White (de Breaking Bad), totalmente egoísta. Não há mais o cowboy que trabalha pelo bem da sociedade. 
$C{ }^{2} E$ : No Brasil, tivemos telenovelas recentes em que a popularidade de personagens vilãs, como a Carminha de Avenida Brasil, chamou atenção. Como você vê essa identificação que a personagem vilã causa no público? $\mathrm{Ou}$, assim como ocorre nas séries, poderíamos dizer que agora o público pode mostrar mais seus sentimentos?

FJ: Não sei bem se o público pode mostrar isso, pois muitas coisas ficam no seu íntimo. Em relação ao personagem Dexter, por exemplo, fala-se de seu lado escuro, de seu lado sombrio. Acho que evidentemente todos nós temos uma parte meio sombria. Penso que essas séries permitem que essas partes se exprimam mais. Dexter diz em um determinado episódio que todo mundo em um determinado momento tem vontade de matar alguém. Essa é uma vantagem das séries, pois tratam isso no plano da ficção. Elas permitem viver pulsões que não podemos viver na vida. É verdade que há também outras coisas. Muitas dessas séries apresentam o voice over, uma via aberta que faz com que penetremos na consciência das personagens. Isso é também uma maneira de construir uma empatia e de ver, de uma maneira ou de outra, o que se passa na cabeça de outras pessoas - nesse caso, de outras personagens.

$C \mathcal{E}{ }^{2} E$ : No seu último livro, La méchanceté en actes à l'ère numérique ${ }^{20}$, você distingue, seguindo uma definição de Vladimir Jankélévitch, a maldade em si e os atos de maldade, a fim de dedicar sua análise aos atos de maldade nos meios de comunicação. Poderíamos dizer que o senhor faz uma espécie de cronologia dos atos de maldade nos meios de comunicação, que ganham terreno também por meio das redes sociais na internet e dos programas de televisão (de ficção ou factuais) ligados à ocorrência da sociedade do espetáculo, discutida por Débord. Você poderia falar um pouco sobre a diferença entre a maldade os atos de maldade e como esses atos ganham um estatuto de espetáculo e frequentemente podem ser compreendidos como "atos de justiça" por um bom número de participantes de redes sociais?

FJ: Jankélévitch distingue entre "ser" mau e "realizar atos de maldade"21. Se a primeira formulação designa um traço de caráter ou um modo de ser relacionado a um indivíduo, a segunda pode se aplicar a cada um de nós, na medida que é possível realizarmos atos de maldade sem sermos maus. Em vez de partir de uma definição a priori de maldade, preferi adotar a abordagem oposta: partir dos atos sentidos como ruins para precisar gradualmente o que significa maldade. Todo mundo tem a experiência de ver a maldade nas redes sociais. O que eu queria fazer não era mostrar que essa maldade é completamente nova, mas trazer à luz as condições que tornaram isso possível, ou, em outras palavras, em que medida a internet tem sido um terreno favorável para essas manifestações. Para isso, retomei a história da mídia e identifiquei três condições. Primeiramente, a "sociedade do espetáculo", no sentido de Débord: "o espetáculo não é um conjunto de imagens, mas uma relação social entre pessoas, midiatizada por imagens”. O que define o espetáculo é que ele transforma a experiência vivida em algo apenas visto e está satisfeito com essa
20. JOST, F. La méchanceté en actes à l'ère numérique. Paris: CNRS Éditions, 2018. 192 p.

21. JANKELEVITCH, V. Traité des vertus: I'innocence et la méchanceté. Paris: Flammarion, 1986. Tomo 3. Coleção Champs. 
aparência. Esta definição é perfeitamente aplicável aos reality shows dos anos 1980-1990, aos quais as pessoas iam para se "mostrar em espetáculo", para resolver problemas íntimos com um psicanalista na frente de um grupo de parentes ou de amigos no estúdio e na frente do público. A partir daí, em segundo lugar, entramos na era do julgamento, que vai se estender na sequência. Programas como Um jantar quase perfeito ${ }^{22}$, no qual os candidatos julgam a refeição para a qual foram convidados, seus anfitriões, a animação do ambiente etc., são apenas um exemplo. Eles são baseados em uma avaliação constante do outro e ecoam sistemas de classificação propostos nos anos 2000 (por exemplo, o Tripadvisor). A terceira condição que favorece essa expansão da maldade é o pseudônimo ou o anonimato. Ao se esconderem atrás de um pseudônimo, todos podem cuspir seu ódio com total impunidade. René Girard ${ }^{23}$ destacou que o verbo krinein, que em grego significa "criticar", passa rapidamente ao significado de "condenar". Isso é exatamente o que as redes sociais ilustram. O problema não é mais dar sua opinião ou dizer sua discordância, mas sim "rebaixar" aquele que é criticado e, em particular, atacar seu status. Por exemplo, toda profissão "não legítima" (filósofo, semiólogo, retórico etc.) se torna um bode expiatório.

$C_{\mathcal{E}}{ }^{2} E$ : Faz bastante tempo que você analisa programas de televisão. Estudando programas ficcionais e reality shows, você falou sobre o impressionante crescimento do culto ao banal e até mesmo sobre o aplauso de boa parte da audiência para os atos de maldade nos reality shows, ao mesmo tempo em que víamos nas séries televisivas a intimidade e falta de caráter de personagens muito populares. Tais características eram mostradas como jamais haviam sido anteriormente. Pensando em termos diacrônicos, no caso específico de personagens de séries de televisão, não poderíamos dizer que o forte desenvolvimento de características de personagens perversos - cada vez mais humanizados e cujos comportamentos criminosos às vezes são mostrados como consequência de uma sociedade implacável (e também perversa) - abre o caminho para o "espetáculo da perversidade", ou até mesmo funciona como uma justificativa para que atos de maldade possam ser expostos com mais liberdade na internet? Em outras palavras, você acredita que existe a possibilidade de encontrar relações entre esses dois movimentos na mídia, em uma espécie de retroalimentação?

FJ: É verdade que, como você diz, já faz muitos anos que falo do "sadismo" do espectador. Algo que às vezes choca os jornalistas, ou pelo menos chocava, porque a ideia hoje é quase admitida. A relação entre a maldade ficcional e a maldade que observamos nos meios de comunicação não é simples. A segunda é a causa da primeira ou a primeira é um sintoma da segunda? É a aporia da

22. Programa do canal de televisão francês M6, exibido de 2008 a 2014, baseado no programa do canal britânico Channel 4, exibido desde 2005.

23. Historiador francês. galinha e do ovo. O que é certo é que as séries às vezes nos proporcionam maior compreensão dos fenômenos que ocorrem na sociedade do que os pesados tratados que deles se ocupam. Como o fato de que a fraqueza das instituições leva a reações violentas. Porém há uma certeza: nos dois casos a maldade 
mais extrema, o ódio, repousa sobre uma vontade de matar o outro. Somente no caso da ficção o verdadeiro malvado não recua diante de nenhuma morte. Já nas redes sociais as mortes são simbólicas: é preciso reduzir o outro ao silêncio, seja desonrando-o até o ponto em que sua voz não seja mais audível, seja levando-o à queda profissional. Penso aqui no caso do ator Kevin Spacey ${ }^{24}$, acusado no contexto da hashtag \#metoo de assediar jovens sexualmente - denúncias que o fizeram desaparecer de um filme que estava sendo gravado, sem ter julgamento (realizado pelo sistema judiciário). Ele não somente foi desligado da série, mas também todas as suas cenas no filme Todo dinheiro do mundo foram refeitas. É uma condenação à morte profissional.

$C \mathcal{E}^{\circ} E$ : Para finalizar, gostaria de retomar uma questão que me parece importante para os pesquisadores que se debruçam sobre o universo das séries. No artigo "Repenser le futur avec les séries. Essai de narratologie comparée" você propõe a utilização das ferramentas de análise da narratologia para o estudo das séries. Como isso poderia ser feito?

FJ: Desde que comecei a pesquisar primeiro a literatura e depois o cinema, sempre considerei que trabalhar um conceito seria trabalhá-lo deslocando-o. No começo trabalhei com Gérard Genette, que construiu conceitos para aplicação na literatura. Tentei ver como tais conceitos funcionavam para os filmes do cinema e percebi que era preciso modificá-los para que fossem aplicados aos filmes. Modificações que, muitas vezes, fazem com que esses conceitos possam voltar para a literatura de uma maneira mais rica. Às vezes, cruzando concepções, encontramos coisas que podem ser generalizadas no domínio do qual partimos. Tento fazer a mesma coisa em relação às séries de televisão. Primeiramente, as séries mudam a própria ideia de narrativa. $O$ filme corresponde a uma velha ideia que se tem de uma narrativa fechada, ou seja, que termina. Nas séries, principalmente nas mais recentes, a narrativa é complexa, pois há alguma coisa que se fecha a cada episódio, mas há algo mais longo, que se fecha após vários episódios, ou mesmo após várias temporadas. Portanto isso nos leva a introduzir dentro desses conceitos, notadamente, a ideia de memória, além de mudar muita coisa... Nas séries, com certeza, nos interessam as imagens e os sons. E os estudos devem abranger diversas temporadas, então não trabalhamos como fazemos com um filme. As personagens também não se constroem como em um filme, o que coloca problemas quando se fazem comparações entre séries, filmes e telenovelas.
24. Em outubro de 2017, o ator Kevin Spacey foi acusado de assédio sexual pelo ator Anthony Rapp. Em consequência dessa acusação e de outras que a sucederam, Spacey foi demitido do elenco da série House of Cards (Netflix, 2013- ) da qual era um dos protagonistas. Além disso, todas as cenas que havia gravado para o filme, All the Money in the World ("Todo dinheiro do mundo"), produzido pela Sony Pictures e dirigido por Ridley Scott, foram refilmadas pelo ator Christopher Plummer. 
